УДК 338.24 .65

\title{
УПРАВЛІННЯ ФІНАНСОВИМИ РЕЗУЛЬТАТАМИ АТ «ОПЕРАТОР ГАЗОРОЗПОДІЛЬНОї СИСТЕМИ «МИКОЛАЇВГАЗ» НА ОСНОВІ ТАКСОНОМІЧНОГО АНАЛІЗУ
}

\author{
MANAGEMENT OF FINANCIAL RESULTS \\ OF JSC «DISTRIBUTION SYSTEM \\ OPERATOR «MYKOLAIVGAS» ON THE BASIS \\ OF TAXONOMIC ANALYSIS
}

\author{
Єрмакова Руслана Русланівна \\ здобувач вищої освіти, \\ Миколаївський національний університет імені В.О. Сухомлинського \\ ORCID: https://orcid.org/0000-0003-2307-3336 \\ Корнєва Наталія Олександрівна \\ кандидат економічних наук, доцент, \\ Миколаївський національний університет імені В.О. Сухомлинського \\ ORCID: https://orcid.org/0000-0002-7309-8673 \\ Ermakova Ruslana, Kornieva Nataliia \\ V.O. Sukhomlynskyi Mykolaiv National University
}

\begin{abstract}
У статті розглянуто основні аспекти таксономічного аналізу як фрактора проведення узагальнюючої оцінки управління фрінансовими результатами суб'єкта господарювання. Для досягнення мети було поставлено такі завдання: дослідити теоретичні аспекти таксономічного аналізу; визначити складові та чинники впливу на матрицю даних; здійснити деталізований аналіз управління фрінансовими результатами за допомогою інструментарію таксономічного аналізу. Обробку інфрормаційних матеріалів здійсненням з використанням сучасних інсрормаційних технологій та програм.
\end{abstract}

Ключові слова: фрінансові результати, управління, суб'єкти підприємництва, таксономічний аналіз, матриця, вектор-еталон.

В статье рассмотрены основные аспекты таксономического анализа, как фрактора проведения обобщающей оценки управления фринансовыми результатами предприятия. Для достижения цели были поставлены следующие задачи: исследовать теоретические аспекты таксономического анализа; определить составляющие и фракторы воздействия на матрицу данных; осуществить детальный анализ управления фринансовыми результатами с помощью инструментария таксономического анализа. Обработку информационных материалов осуществлением с использованием современных инорормационных технологий и программ.

Ключевые слова: финансовые результаты, управления, субъекты предпринимательства, таксономический анализ, матрица, вектор-эталон.

The article considers the main aspects of taxonomic analysis as a factor in conducting a general assessment of the management of financial results of the entity. The purpose of this article is: to study the theoretical aspects of the methodology of construction of the taxonomic indicator, calculation of the integrated indicator, systematization of elements of the observation matrix and construction of the indicator of financial performance management JSC "Distribution System Operator Mykolaivgaz». To achieve this goal, the following tasks were set: to investigate the theoretical aspects of taxonomic analysis; determine the components and factors influencing the data matrix; perform a detailed analysis of financial performance management using taxonomic analysis tools. Algorithms of taxonomic analysis and distance and similarity method are systemized, generalized, itemized and presented as technological schemes with consideration of innovations in the format of their practical use. The article develops recommendations on increase of accuracy and justification of joint assessments, which take into account results of the classical and modified algorithms of building multi-dimensional assessments within the framework of each method. 
Research favors the basis for the implementation of measures to increase the efficiency of the economic potential of the enterprise and improve the mechanism of financial performance management. Based on the application of the method of taxonomic analysis, it is shown how synthetic values of the taxonomic index of solvency are calculated and taxonomic indicators of financial results of the enterprise. According to research, taxonomic methods for assessing the level of enterprise development are quite simple to use, universal and comprehensively analyze the state of the enterprise. The results will contribute to the formation of new methodological approaches to make operational management decisions to improve financial performance. Processing of information materials by implementation with the use of modern information technologies and programs.

Keywords: financial results, management, business entities, taxonomic analysis, matrix, reference-vector.

Постановка проблеми: Управління фрінансовими результатами суб'єкта підприємництва обумовлює необхідність застосування порівняльного аналізу, що полягає у співставленні даних про результати господарювання. Такий аналіз вимагає значної кількості показників, які дозволять надати всебічну характеристику об'єкта дослідження та більш повно розкрити перспективи розвитку суб'єкта господарювання [1].

Тому дослідження управління фрінансовими результатами та виявлення наявних проблем, а також визначення перспективних напрямків його розвитку є актуальним і своєчасним.

Аналіз останніх досліджень і публікацій: Вивчення фрахової літератури дозволило встановити, що в багатьох наукових працях розглядаються питання пов'язані із напрямками стійкого розвитку як окремого підприємства, так і складних систем в цілому. Значна кількість вчених-економістів приділяє цьому аспекту значну увагу, а саме Ю.П. Анісімов, Ю.В. Журавльов, Н.А. Флут. Разом з тим дана модель буде мати практичну значимість у випадку можливості оцінки об'єктів, що входять до її складу.

Мета статті. Метою даної статті $\epsilon$ : вивчення теоретичних аспектів методики побудови таксономічного показника, розрахунок інтегрального показника, систематизація елементів матриці спостережень та побудова показника ефективності управління фрінансовими результатами АТ «Оператор газорозподільної системи «Миколаївгаз».

Виклад основного матеріалу дослідження. У загальному вигляді проблему упорядкування багатовимірних об'єктів або процесів щодо заданого нормативного вектора-еталона вирішує таксономія. На основі методу таксономії можливою $€$ побудова узагальнюючої оцінки складного об'єкта або процесу [2].

При побудові таксономічного показника застосовується матриця даних або складена зі стандартизованих реалізації ознак Одночасно відбувається вирівнювання дисперсії (кожна дисперсія стає рівною одиниці), а також значень ознак (усі середні арифметичні рівняються нулю), що небажано, тому що через це кожна ознака однаковою мірою впливає на результати аналізу [3].

Крім цього, всі показники, що взяті в основу дослідження, поділяються на стимулятори, ті, що позитивно впливають на синтетичний, і на дестимулятори, що гальмують його розвиток.

При розрахунках таксономічного показника запропоновано методику його побудови (рис. 1).

На першому етапі здійснюється формування матриці спостережень (Z), яка може бути представлена таким чином (формула 1 ):

$$
\mathrm{Z}=\left\{\begin{array}{ccccc}
\mathrm{X}_{11} & \mathrm{X}_{12} & \ldots & \mathrm{X}_{i j} & \mathrm{X}_{1 n} \\
\mathrm{X}_{21} & \mathrm{X}_{22} & \cdots & \mathrm{X}_{i j} & \mathrm{X}_{2 n} \\
\cdots & \cdots & & \cdots & \cdots \\
\mathrm{X}_{i 1} & \mathrm{X}_{i 2} & \ldots & \mathrm{X}_{i j} & \mathrm{X}_{i n} \\
\cdots & \ldots & & \cdots & \cdots \\
\mathrm{X}_{m 1} & \mathrm{X}_{m 2} & \ldots & \mathrm{X}_{m j} & \mathrm{X}_{m n}
\end{array}\right\}
$$

Вихідними даними для побудови матриці відібрано показники, які, на нашу думку, найбільш істотно впливають на орінансовий результат суб'єкта підприємництва та на основі яких буде розраховано таксономічний показник (табл. 1).

Елементи цієї матриці - це показники, виражені в спеціальних ознаках в одиницях виміру. Тому для проведення наступних розрахунків необхідна стандартизація, яка дозволить звести всю одиницю виміру до безрозмірної величини, тобто вирівняти значення ознак [4].

Стандартизуємо значення елементів матриці спостережень. Для цього визначаємо середнє значення по кожному показнику:

$$
\begin{aligned}
& X_{1 c p}=-46183 \\
& X_{2 c p}=-151392 \\
& X_{3 c p}=-42,13 \\
& X_{4 c p}=-19,22 \\
& X_{5 c p}=-91,21 \\
& X_{6 c p}=109561,3 \\
& X_{7 c p}=2,79 \\
& X_{8 c p}=-347382
\end{aligned}
$$

Стандартизувати показники можна за наступною фрормулою 2:

$$
\mathrm{Zi}=\frac{X i}{\bar{X}}
$$




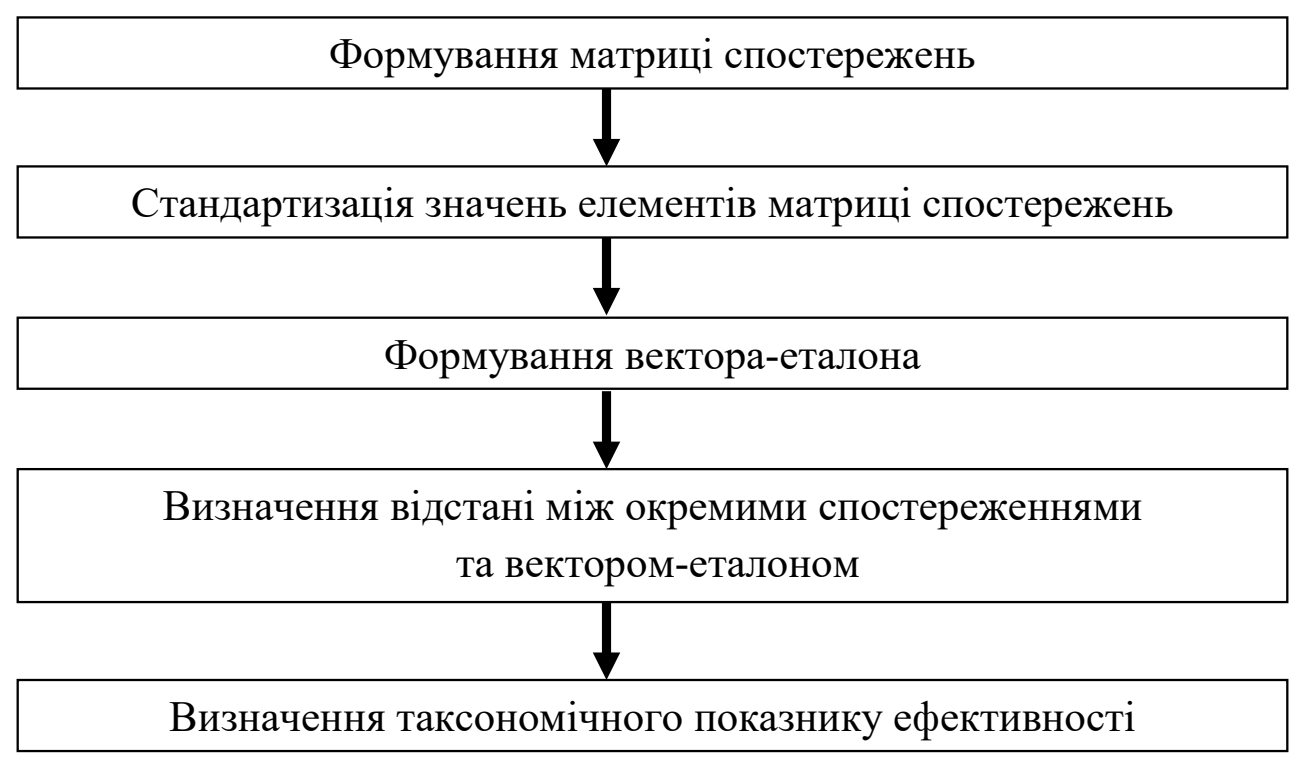

Рис. 1. Методика побудови таксономічного показника Джерело: [6]

Побудова показника ефективності управління фрінансовими результатами полягає у визначенні елементів матриці спостережень та їх стандартизації, після чого проводиться дисреренціація ознак. При цьому всі змінні необхідно поділити на стимулятори та дестимулятори.
Поділ ознаки на стимулятори й дестимулятори - основа для побудови вектора-еталона [6]. Елементи цього вектора мають координати та фрормуються за рахунок значень показників за фрормулою 3 :

$$
\left\{\begin{array}{c}
x_{0 i}=\max x_{i j}(\text { стимулятор }) \\
x_{0 i}=\min x_{i j}(\text { дестимулятор })
\end{array}\right\}
$$

\section{Вихідні дані для розрахунку таксономічного показника управління фрінансовими результатами}

АТ «Оператор газорозподільної системи «МИКОЛАЇВГАЗ» за 2018-2020 роки

\begin{tabular}{|c|c|c|c|c|c|c|c|c|}
\hline $\begin{array}{l}\text { Періодl } \\
\text { Показник }\end{array}$ & 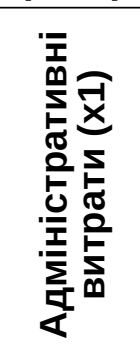 & 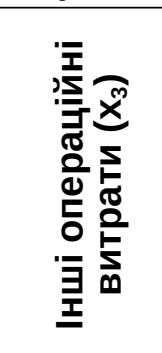 &  & 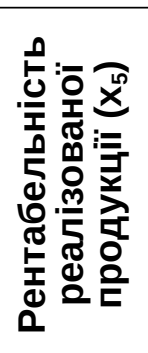 & 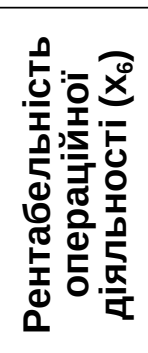 &  & 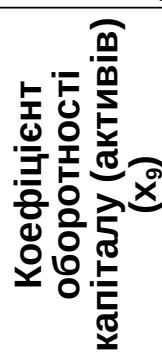 & 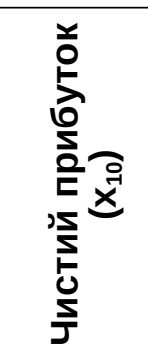 \\
\hline & 37 & -289026 & & & $-91,84$ & 249423 & $-1,76$ & -440677 \\
\hline & -465 & $-3391 /$ & $-48,5$ & $-23,24$ & $-83,93$ & 94915 & -4 & -379969 \\
\hline 2020 & -58309 & -131235 & $-27,7$ & $-13,03$ & $-97,88$ & -15654 & 14,14 & -221500 \\
\hline
\end{tabular}

Джерело: складено авторами за [5; 7]

Таблиця 1

Таблиця 2

Система стандартизованих даних для оцінки рівня платоспроможності АТ «Оператор газорозподільної системи «МИКОЛАЇВГАЗ»

\begin{tabular}{|c|c|c|c|c|c|c|c|c|}
\hline & $\mathbf{X}_{\mathbf{1}}$ & $\mathbf{X}_{\mathbf{2}}$ & $\mathbf{X}_{\mathbf{3}}$ & $\mathbf{X}_{\mathbf{4}}$ & $\mathbf{X}_{\mathbf{5}}$ & $\mathbf{X}_{\mathbf{6}}$ & $\mathbf{X}_{\mathbf{7}}$ & $\mathbf{X}_{\mathbf{8}}$ \\
\hline \multirow{3}{*}{$\mathrm{Z}=$} & 0,72 & 1,9 & 1,19 & 1,11 & 1,001 & 2,27 & $-0,63$ & 1,26 \\
\cline { 2 - 9 } & 1,01 & 0,22 & 1,15 & 1,20 & 0,920 & 0,86 & $-1,43$ & 1,09 \\
\cline { 2 - 8 } & 1,26 & 0,86 & 0,65 & 0,67 & 1,07 & 0,14 & 5,06 & 0,63 \\
\hline
\end{tabular}


Сутність фрормування вектора-еталона полягає в наступному: якщо частковий показник $€$ стимулятором, то за еталон визначається його максимальне значення, якщо дестимулятором - мінімальне значення. Вектор еталон має наступний вигляд (фрормула 4):

$$
P_{0}=\left(\mathrm{X}_{01}, \mathrm{X}_{02}, \ldots, \mathrm{X}_{0 \mathrm{~m}}\right) \text {, }
$$

Таким чином, вектор-еталон АТ «Оператор газорозподільної системи «МИКОЛАЇВГАЗ» має такі координати (табл. 3).

Наступним етапом визначення таксономічного показника платоспроможності $€$ визначення відстані між окремими спостереженнями (періодами) і вектором-еталоном [5].

$$
C_{i o}=\sqrt{\sum_{i=1}^{m}(z i j-z o j)^{2}}
$$

Для АТ «Оператор газорозподільної системи «МИКОЛАЇВГАЗ» за 2018-2020 значення відстані між точкою - одиницею та точкою РО дорівнює:

$$
\begin{aligned}
& C_{i 0} 2018=0,518 ; \\
& C_{i 0} 2019=0,891 ; \\
& C_{i 0} 2020=0,918 .
\end{aligned}
$$

Отримана відстань $є$ початковою для розрахунку показника платоспроможності підприємства.

Показник середньої відстані між спостереженнями розраховуємо за фрормулою 6:

$$
\overline{C_{0}}=\frac{1}{m} \sum_{i=1}^{m} C_{i 0},
$$

де - $m$-кількість періодів;

$C_{i 0}-$ відстань між точкою-одиницею й точкою $\mathrm{P}_{0}$.

Середня відстань між спостереженнями для АТ «Оператор газорозподільної системи «МИКОЛАЇВГАЗ» становить $\bar{C}_{0}=0,776$.

Розрахунок середнього значення кореня квадратного середнього квадрата різниці значень ознак здійснюється за фрормулою 1.7:

$$
S_{0}=\sqrt{\frac{1}{m} \sum\left(C_{i 0}-\bar{C}_{0}\right)},
$$

Середнє значення кореня квадратного середнього квадрата різниці значень ознак АТ «Оператор газорозподільної системи «МИКОЛАїВГАЗ» становить $-S_{0}=0,105$;

Максимальне відхилення від сорормованного вектора визначається за фрормулою 8:

$$
C_{0}=\bar{C}_{0}+2 S_{0},
$$

Максимальне відхилення від сфрормованного вектора АТ «Оператор газорозподільної системи «МИКОЛАЇВГАЗ» становить $-C_{0}=0,986$.

Зведений динамічний показник di визначається за фрормулою 9:

$$
d_{i}=\frac{C_{i 0}}{C_{0}} .
$$

Зведений динамічний показник АТ «Оператор газорозподільної системи «МИКОЛАЇВГАЗ» за 2018-2020 роки становить:

$d_{i} 2018=0,525 ;$
$d_{i} 2019=0,903 ;$
$d_{i} 2020=0,931$.

Визначаємо таксономічний показник платоспроможності $\left(K_{i}\right)$ за фрормулою 10:

$$
K_{i}=1-d_{i},
$$

Таксономічний показник платоспроможності АТ «Оператор газорозподільної системи «МИКОЛАЇВГАЗ» за 2018-2020 роки:

$$
\begin{aligned}
& K_{i} 2018=0,084 ; \\
& K_{i} 2019=0,863 ; \\
& K_{i} 2020=0,639 .
\end{aligned}
$$

Інтерпретація даного показника наступна: він приймає високі значення при більших значеннях стимуляторів і низькі значення - при малих значеннях стимуляторів.

Висновки та пропозиції. Підсумовуючи зазначено, що коефріцієнт таксономії управління фрінансовими результатами АТ «Оператор газорозподільної системи «МИКОЛАїВГАЗ» $€$ нестабільним протягом 2018-2020 років. Чим більш близький цей показник до 1, тим вищій рівень ефрективності управління фрінансовими результатами.

Запропонований показник дає можливість отримати комплексну ефективність управління фрінансовими результатами підприємства, виявити фрактори, що спричиняють негативний вплив на неї, та сорормувати шляхи підвищення рівня ефрективності управління орінансовими результатами суб'єкта господарювання.

Тому пропонуємо АТ «Оператор газорозподільної системи «МИКОЛАЇВГАЗ» використовувати таксономічний аналіз управління фрінансовими результатами, щоб спостерігати за стабільністю показників протягом року.

Таблиця 3

Координати вектора-еталона АТ «Оператор газорозподільної системи «МИКОЛАЇВГАЗ»

\begin{tabular}{|c|c|c|c|c|c|c|c|c|}
\hline & $\mathbf{X}_{1}$ & $\mathbf{X}_{2}$ & $\mathbf{X}_{\mathbf{3}}$ & $\mathbf{X}_{4}$ & $\mathbf{X}_{5}$ & $\mathbf{X}_{6}$ & $\mathbf{X}_{\mathbf{7}}$ & $\mathbf{X}_{\mathbf{8}}$ \\
\hline $\mathrm{P}_{0}=$ & 0,72 & 0,22 & 0,65 & 0,67 & 0,92 & 0,14 & $-1,43$ & 0,63 \\
\hline
\end{tabular}




\section{СПИСОК ВИКОРИСТАНИХ ДЖЕРЕЛ:}

1. Педченко Н.С. Гармонізація управління процесом орормування потенціалу розвитку підприємств та організацій споживчої кооперації на основі методу таксономії. URL: http://www.dspace.puet.edu.ua/ bitstream/123456789/4391/1/business-inform-2012-8_0-pages-11_17.pdf

2. Плюта В. Сравнительный многомерный анализ в экономических исследованиях. Методы таксономии и фракторного анализа. Москва : Статистика, 1980. 151 с.

3. Рєпіна І.М. Таксономічний аналіз ефективності фрормування та використання активів підприємства. Формування ринкової економіки. 2011. № 26. С. 440-457.

4. Сабліна Н.В., Теличко В.А. Використання методу таксономії для аналізу внутрішніх ресурсів підприємства. Бізнес Інфрорм. 2009. № 3. С. 78-82.

5. Фінансовий аналіз : посібник / За заг. ред. Н.О. Корнєва. Вид. 2-ге, перероб. та доп. Миколаїв : Іліон, 2016. 228 C.

6. The IFRS Taxonomy Illustrated.IFRS Taxonomy 2017 Taxonomy Update 1. A view of the IFRS Taxonomy 2017 Taxonomy Update 1 (organised by IFRS Standards). URL: https://www. ifrs.org/-/media/project/ifrs-taxonomyupdate-insurance-contracts/ ifrs-taxonomy-illustrated-2017-by-ifrs-standards.pdf

7. Офріційний сайт АТ «Оператор газорозподільної системи «МИКОЛАїВГАЗ». URL: https://mk.dsoua.com/ua/

\section{REFERENCES:}

Pedchenko N.S. (2012) Harmonizatsiya upravlinnya protsesom formuvannya potentsialu rozvytku pidpryyemstv ta orhanizatsiy spozhyvchoyi kooperatsiyi na osnovi metodu taksonomiyi [Harmonization of management of process of formation of potential of development of the enterprises and the organizations of consumer cooperation on the basis of a method of a taxonomy]. Retrieved from: http://www.dspatse.puet.edu.ua/ bitstream/123456789/4391/1/business-inform-2012-8_0-pages-11_17.pdf

1. Plyuta V. (1980) Sravnitelnyj mnogomernyj analiz v ekonomicheskih issledovaniyah. Metody taksonomii $\mathrm{i}$ faktornogo analiza [Comparative multidimensional analysis in economic research. Methods of taxonomy and factor analysis]. Moscow: Statistika, $151 \mathrm{p}$.

2. Ryepina I. (2011) Taksonomichnij analiz efektivnosti formuvannya ta vikoristannya aktiviv pidpriyemstva [Taxonomic analysis of the efficiency of formation and use of enterprise assets]. Formuvannya rinkovoyi ekonomiki, no. 26 , pp. 440-457.

3. Sablina N.V., Telichko V.A. (2009) Ispolzovanie metoda taksonomii dlya analiza vnutrennih resursov predpriyatiya [Using the method of taxonomy to analyze the internal resources of the enterprise]. Biznes Inform, no. 3, pp. 78-82.

4. Kornieva N. (2016) Finansovij analiz: Posibnik[Financial Analysis: A Guide] / Vid. 2-ge, pererob. ta dop. Mikolaiv: Ilion, $228 \mathrm{p}$.

5. The IFRS Taxonomy Illustrated.IFRS Taxonomy 2017 Taxonomy Update 1. A view of the IFRS Taxonomy 2017 Taxonomy Update 1 (organised by IFRS Standards).

6. Oficijnij sajt AT «Operator gazorozpodilnoyi sistemi «MIKOLAYiVGAZ» [Official site of JSC "Gas Distribution System Operator "MYKOLAYIVGAS" Access model]. Retrieved from: https://mk.dsoua.com/ua/- 